\title{
Effects of Citrulline Malate Supplementation on Aerobic and Muscular Endurance in Young Adults Men
}

\section{Efeitos da Suplementação de Citrulina Malato sobre a Resistência Aeróbica e Muscular em Homens Adultos Jovens}

\author{
Alan Pablo Grala; Éderson Candellório; ${ }^{a}$ Paulo Henrique Sperandio ${ }^{a}$; Emilly Aparecida da Gama Maldonadoa ${ }^{a}$ Bruno \\ Henrique Beltramel dos Anjos ${ }^{\mathrm{a}}$; Jeferson Lucas Jacinto ${ }^{\mathrm{b}}$; Juliano Casonatto ${ }^{\mathrm{c}}$; Andreo Fernando Aguiar*bc \\ aParanaense University, Physical Education Department. PR, Brazil. \\ ${ }^{b}$ Unopar, Stricto Sensu Graduate Program in Rehabilitation Sciences. PR, Brazil. \\ 'Unopar, Stricto Sensu Program in Physical Exercise in Health Promotion. PR, Brazil. \\ *E-mail: andreo.aguiar1@kroton.com.br \\ Recebido em: 19/10/2020 \\ Aprovado em: 07/12/2020
}

\begin{abstract}
The aim of this study was to evaluate the effects of citrulline malate (CIT) supplementation on aerobic and muscular endurance in young adult males. Eighteen young adult men (age: $21.5 \pm 2.7$ years) were randomized into two groups (Citrulline malate - CIT and Placebo - PLA; $\mathrm{N}=9$ / group ) and received the respective supplements for 7 days. The CIT group was supplemented with $6 \mathrm{~g}$ CIT $+6 \mathrm{~g}$ dextrose (total: $12 \mathrm{~g}$ ), while the PLA group received the same amount $(12 \mathrm{~g})$ of dextrose. At the pre- and post-supplementation, the following variables were analyzed: aerobic (maximal treadmill test, $\mathrm{T}_{\max }$ ) and muscle (repetitions maximum test, $\mathrm{R}_{\max }$ ) endurance tests, as well as mean and maximum heart rate (HR) in $\mathrm{T}_{\max }$ and ratings of perceived exertion (PSE) in $\mathrm{R}_{\max }$. No significant $(P>0.05)$ differences were found between CIT and PLA groups in time until exhaustion in $\mathrm{T}_{\max }$, total repetitions in $\mathrm{R}_{\max }$, maximal HR and PSE from pre- to post-supplementation. The mean HR was statistically lower $(P<0.05)$ in the CIT group compared to the PLA in the $\mathrm{T}_{\max }$. In conclusion, supplementation of CIT $(6 \mathrm{~g} /$ day) does not improve aerobic and muscular endurance, as well as maximal HR or PSE in healthy young adults, despite reducing the mean HR during the maximal incremental test.
\end{abstract}

Keywords: Endurance Training. Dietary Supplements. Physical Functional Performance. Citrulline. Nitric Oxide.

\section{Resumo}

O objetivo deste estudo foi avaliar os efeitos da suplementação de citrulina malato (CIT) sobre a resistência aeróbica e muscular em homens adultos jovens. Em um desenho experimental randomizado, duplo-cego e controlado com placebo, dezoito homens adultos jovens (idade: 21,5 $\pm 2,7$ anos) foram randomizados em dois grupos (Citrulina malato - CIT e Placebo - PLA; $N=9 / g r u p o$ ) e receberam os respectivos suplementos por um período de 7 dias. O grupo CIT foi suplementado com $6 \mathrm{~g}$ de CIT $+6 \mathrm{~g}$ de dextrose (total: $12 \mathrm{~g}$ ), enquanto o grupo PLA recebeu a mesma quantidade (12 g) de dextrose. Nos momentos pré e pós suplementação as seguintes variáveis foram analisadas: resistência aeróbia (teste incremental máximo em esteira rolante, $T_{\text {máx }}$ ) e muscular (teste de repetições máximas, $R_{\text {máx }}$ ), bem como a frequência cardíaca (FC) média e máxima no $T_{\text {mix }}$ e a análise da percepção subjetiva de esforço (PSE) no $R_{\text {maxx }}$ Nenhuma diferença significante (P > 0,05) foi encontrada entre os grupos CIT e PLA no tempo até a exaustão no $T_{\text {maxx }}$, total de repetições no $R_{\text {máx }}$ FC máxima e PSE do momento pré para o pós suplementação. A FC média foi estatisticamente $\left(_{P<0,0.5}\right)$ menor no grupo CIT comparado ao PLA no $T_{\max }$. Em conclusão, a suplementação de CIT (6 g/dia) não melhora a resistência aeróbica e muscular, bem como a FC máxima ou PSE em adultos jovens saudáveis, apesar de reduzir a FC média durante o teste incremental máximo.

Palavras-chave: Treino Aeróbico. Suplementos Nutricionais. Desempenho Físico Funcional. Citrulina. Óxido Nítrico.

\section{Introduction}

Nutritional supplementation is a strategy commonly used by athletes and recreational practitioners in an attempt to improve physical performance and muscle recovery. Among the most widely used supplements, malate citrulline amino acid (CIT) has received special attention in recent years due to its supposed ergogenic effects ${ }^{1-3}$ under various physical exercise conditions. CIT is formed by the combination of L-citrulline and malate (or malic acid) - a salt found mainly in apples. The potential ergogenic effects of CIT have been attributed to three main mechanisms: First, L-citrulline supplementation seems to increase L-arginine plasma levels ${ }^{4-6}$ under rest and physical exercise conditions. Considering that L-arginine is the main substrate for nitric oxide synthesis (ON), an important blood flow modulator ${ }^{7}$, it has been suggested that CIT supplementation can indirectly increase ON synthesis ${ }^{8}$ and thus increase blood flow to the active muscles. As a result, CIT supplementation could increase the release of nutrients and/or the removal of metabolic residues ${ }^{9,10}$ (e.g. lactate and ammonia), improving the muscle function ${ }^{11}$.

Furthermore, citrulline is an essential component of the urea cycle in the liver ${ }^{12}$, in which L-arginine produced from citrulline is catalyzed by arginase in ornithine and urea. Considering that urea is the main vehicle for eliminating ammonia - a promoter of muscle fatigue through anaerobic glycolysis and resulting lactic acid production ${ }^{13}$ - it has been suggested that supplementation with CIT can improve 
ammonia homeostasis ${ }^{14}$ and, consequently, muscle function. Finally, malate is an intermediate of the Krebs cycle and its greater availability after supplementation with CIT seems to increase ATP production through anaplastic Krebs cycle reactions ${ }^{2}$, resulting in decreased muscle fatigue and increased muscle performance ${ }^{2,8,15}$.

Based on the above mechanisms, it has been postulated that CIT supplementation can increase the physical performance in several ways, including reduction of muscle pain $^{8}$ and fatigue ${ }^{2}$, increased oxygen release to active muscles ${ }^{2}$, increased ATP production during exercise and creatine phosphate $(\mathrm{CP})$ concentrations during recovery ${ }^{2}$, and decreased lactate and ammonia production ${ }^{16-18}$. However, recent studies do not confirm such beneficial effects of CIT (6-8 g) on recovery indicators (creatine kinase, lactate, and maximum repetitions) ${ }^{19}$ and muscle performance (number of repetitions and pain level) ${ }^{13,20,21}$, as well as on aerobic (time to exhaustion) and anaerobic (lactate threshold) activities ${ }^{13}$ and fatigue markers (lactate) ${ }^{15,22}$. Therefore, there are still doubts whether CIT supplementation can be effective to improve physical performance, especially in activities related to aerobic and muscular resistance.

The objective of this study was to investigate the CIT supplementation effects on aerobic and muscular resistance in young adult individuals. Based on the physiological properties and supposed ergogenic effects of $\mathrm{CIT}^{8,15,20}$, the hypothesis was tested that CIT supplementation could increase the time until exhaustion and the number of maximum repetitions, as well as reduce the heart rate (HR) and the effort subjective perception (PSE) in the respective tests.

\section{Material and Methods}

\subsection{Participants}

Eighteen young adult men (age $21.5 \pm 2.7$ years) were selected from a university population to compose the sample of this study, according to the following inclusion criteria: a) not presenting history of musculoskeletal or cardiac dysfunctions or pathologies, b) not being a user of medications that affect or potentiate physical performance, c) not having used nutritional supplements or steroids for at least 6 months prior to the beginning of the study, and d) not having presented a medical restriction for maximum physical testing. The participants were recruited by means of project disclosure at the Institution (classroom visit, information posters and e-mail) and selected by interview and clinical anamnesis. All participants were duly informed about the objectives, risks and benefits of the research and signed a free and informed consent form approved by the Ethics Committee of the institution (opinion: 2.184.147).

\subsection{Experimental design}

This study used a randomized, double-blind, placebocontrolled experimental design (Figure 1). Initially, all the participants were submitted to 3 familiarization sessions (days $0-2$ ), being 1 session for the maximum incremental treadmill test $\left(\mathrm{T}_{\max }\right)\left(\right.$ Embreex $^{\circledR}$, Brusque, Brazil) and 2 sessions for the practice of leg extension exercise in the leg extension machine (Movement ${ }^{\mathbb{R}}$, Sao Paulo, Brazil). Subsequently, the participants performed 3 test sessions of a maximum repetition $(1 \mathrm{RM})$ in the leg extension machine (days 4-6), 1 test session $\mathrm{T}_{\max }$ (i.e. time to exhaustion), including the measurement of HR (day 8), and 1 test session of maximum repetitions $\left(\mathrm{R}_{\max }\right)$, including the analysis of effort subjective perception (PSE) (day 11). Finally, the participants were randomized into two groups (Citrulline - CIT and placebo - PLA; $\mathrm{N}=9$ /group) and received the respective supplements for a period of 7 days (days 12-18). At the end of supplementation, the groups were reassessed (days 19-21) in $\mathrm{T} \max$ and $\mathrm{R}_{\max }$, tests in order to investigate the possible CIT supplementation effects on aerobic (time to exhaustion) and muscular (number of maximum repetitions) resistance.

Figure 1 - Experimental drawing.

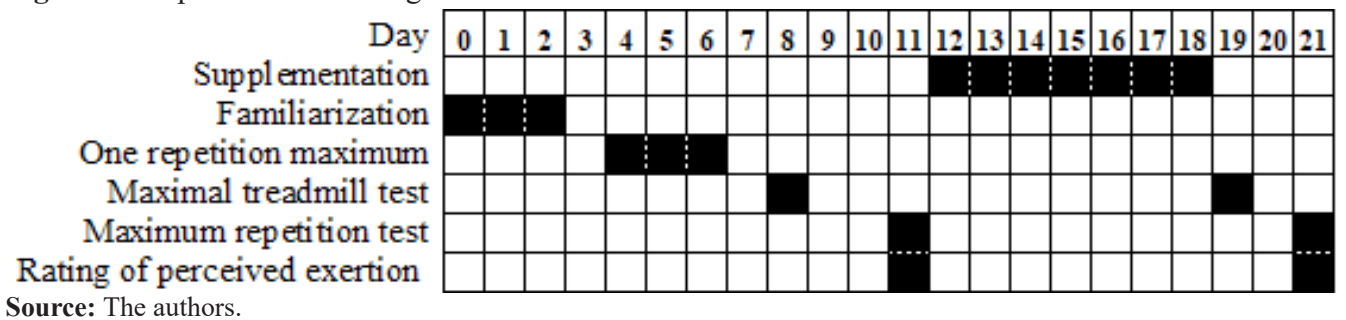

\subsection{Familiarization}

During familiarization (days 0-2), the participants performed a $\mathrm{T}_{\text {max }}$ test (day 0 ), which consisted of a prior warm up to $6 \mathrm{~km} / \mathrm{h}$ for 3 minutes and subsequent speed increment $(1.2 \mathrm{~km} / \mathrm{h})$ every 3 minutes until the participant reported exhaustion (inability to continue the test). The treadmill was maintained at a $1 \%$ slope during the test. In addition, the participants were submitted to two sessions (days 1-2) of leg extension exercise in the leg extension machine, consisting of 4 series of 10-12 repetitions, with a 2-minute interval between the series. The participants were also familiar with the PSE scale (score: 6-20) of $\mathrm{BORG}^{23}$, being considered ' 6 ' no effort and '20' maximum effort.

\subsection{One repetition maximum test (1RM)}

The load of 1RM was determined to establish the load for 
the maximum repetition test $(60 \%$ of $1 \mathrm{RM})$ at pre- and postsupplementation moments. Briefly, the participants performed a specific muscle warm up at the own leg extension machine, consisting of 3 series of 8 (50\% of estimated 1RM), 5 (70\% of estimated $1 \mathrm{RM})$ and $2(85 \%$ estimated $1 \mathrm{RM})$ repetitions, respectively, with a 2-minute interval between each series. At the end of the warm up, the individuals were instructed to perform 2 repetitions in the first attempt of the test, with a load established by the evaluators. According to the number of repetitions performed on the first attempt, additional loads $(\sim 5 \%)$ were added on subsequent attempts until the participant performed only one maximum repetition (1RM). Three attempts were allowed on each test day (days 4-6), with a 5-minute interval between each attempt. During the tests, the individuals were continuously monitored and verbally encouraged by the evaluators. The participants were instructed to avoid any type of extenuating physical activity for a period of at least 24 hours before the 1RM tests.

\subsection{Maximum repetitions test $\left(R_{\text {max }}\right)$}

The $\mathrm{R}_{\max }$ test was performed at the pre- and postsupplementation moments (days 11 and 21) and consisted in performing as many repetitions as possible at $60 \%$ of $1 \mathrm{RM}$ until muscle failure (inability to perform new repetitions in all range of motion $)^{24}$. The PSE session was determined using the BORG scale (intensity: 6-20) ${ }^{23}$, immediately after the test completion. During the tests, the participants were continuously monitored and verbally encouraged by the evaluators.

\subsection{Maximum incremental treadmill test $\left(T_{\max }\right)$}

The $\mathrm{T}_{\max }$ test was performed at the pre- and postsupplementation moments (days 8 and 19), in order to investigate the time until exhaustion, as a direct indicator of aerobic resistance. The test consisted of a prior warm up to $6 \mathrm{~km} / \mathrm{h}$ for 3 minutes and subsequent speed increment (1.2 $\mathrm{km} / \mathrm{h}$ ) every 3 minutes until the participant reported exhaustion (inability to continue the test). The treadmill was maintained at a $1 \%$ slope during the test. Speed increment every 3 minutes was chosen because it was reliable and valid for the submaximal and maximal measurement of physiological variables $^{25}$. Mean and maximum HR was measured during the test with the Polar ${ }^{\circledR} \mathrm{H} 10$ (POLAR, Finland) HR transmitter and Polar ${ }^{\circledR}$ Beat recording and monitoring software (POLAR, Finland). During the tests, the participants were continuously monitored and verbally encouraged by the evaluators.

\subsection{Supplementation}

The CIT group was supplemented with $6 \mathrm{~g} \mathrm{CIT}+6 \mathrm{~g}$ dextrose (total: $12 \mathrm{~g}$ ), while the PLA group received the same amount (12 g) of dextrose. The groups were randomized and double blind supplemented for a period of 7 days (days 12-18). A 6-g dose of CIT was chosen based on previous studies that demonstrated an increase in plasma citrulline concentrations after intense exercise in cyclists ${ }^{26}$, without any adverse effect ${ }^{27}$. To ensure double-blind design, an individual who was not involved in the study was responsible for placing the supplements in bags and labeling the sachets with the participants' names, according to the randomization list. Supplements were always consumed at the same time of day, at 06 p.m.

\subsection{Statistical Analysis}

Data were expressed as mean \pm standard deviation (SD). ANOVA tests for repeated measures (Groups: 2 x Time: 2), complemented by Bonferroni's test, were used to analyze changes in time (Pre and Post) and between groups (CIT and PLA) for all the dependent variables (time to exhaustion, number of maximum repetitions, HR and PSE). The violation of sphericity was adjusted by the greenhouse-Geisser correction. Baseline data were analyzed using the non-paired $\mathrm{t}$ test. The significance level was $P<0.05$. Data were analyzed using SPSS software (version 20.0; Chicago, IL, USA).

\section{Results and Discussion}

\subsection{Basal characteristics}

No significant difference $(P>0.05)$ was observed in basal characteristics between CIT and PLA groups (Table 1). All the participants ( $\mathrm{N}=9$ /group) completed the experiment, and no adverse effects were reported throughout the study.

Table 1 - Basal characteristics of the participants

\begin{tabular}{|l|c|c|c|}
\hline & CIT $(N=9)$ & PLA $(N=9)$ & $P$ value \\
\hline Age (years) & $21.0 \pm 2.8$ & $22.1 \pm 2.6$ & 0.40 \\
\hline Body mass $(\mathrm{kg})$ & $76.7 \pm 7.3$ & $80.9 \pm 11.2$ & 0.36 \\
\hline Height $(\mathrm{cm})$ & $177.5 \pm 5.6$ & $176.7 \pm 5.0$ & 0.74 \\
\hline BMI $\left(\mathrm{Kg} / \mathrm{m}^{2}\right)$ & $24.3 \pm 1.9$ & $26.0 \pm 4.3$ & 0.30 \\
\hline
\end{tabular}

Values are expressed in mean \pm standard deviation.

Source: Research data.

\subsection{Time to exhaustion}

No significant difference $(P>0.05)$ was found in the time until exhaustion between CIT and PLA groups (Figure 2) from the pre-post supplementation moment (CIT, Pre: $891 \pm 227$ and Post: $932 \pm 241$ vs. PLA, Pre $739 \pm 226$ and Post: $750 \pm 165$ ).

Figure 2 - Time to exhaustion in the maximum incremental test $\left(\mathrm{T}_{\max }\right)$ in the malate citrulline (CIT, $\left.N=9\right)$ and placebo groups (PLA, $N=9$ ) at pre- and post-supplementation moments. Values expressed in mean $\pm \mathrm{SD}$. No significant difference $(P>0.05)$ was observed between the groups

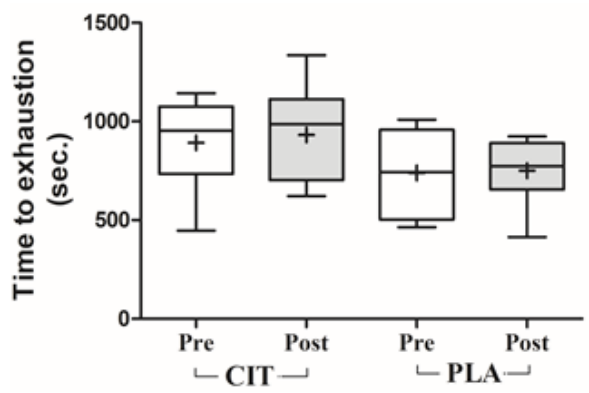

Source: The authors 


\subsection{Mean and maximum HR}

No significant difference $(P>0.05)$ was found in maximum HR between CIT and PLA groups (Figure 3A) from the pre-post supplementation moment (CIT, Pre: $179 \pm$ 3 and Post: $177 \pm 6$ vs. PLA, Pre: $178 \pm 2$ and Post: $179 \pm$ $2)$. On the other hand, there was a significant reduction $(P)$ in mean HR in the CIT group, compared to the PLA group, from the pre-post supplementation moment (Figure 3B). This reduction was evidenced in 6 sample participants (Figure 3B, upper right corner), indicating that the CIT effects may be influenced by the participant's responsiveness.

Figure 3 - Maximum heart rate (HR) (A) and mean heart rate (B) in the maximum incremental test $\left(\mathrm{T}_{\max }\right)$ in the malate citrulline (CIT, $N=9$ ) and placebo groups (PLA, $N=9$ ) at pre- and postsupplementation. Right upper panel shows the individual variation of mean HR in CIT group from the pre-post supplementation moment. Values expressed in mean \pm SD. * Significant difference between CIT and PLA groups
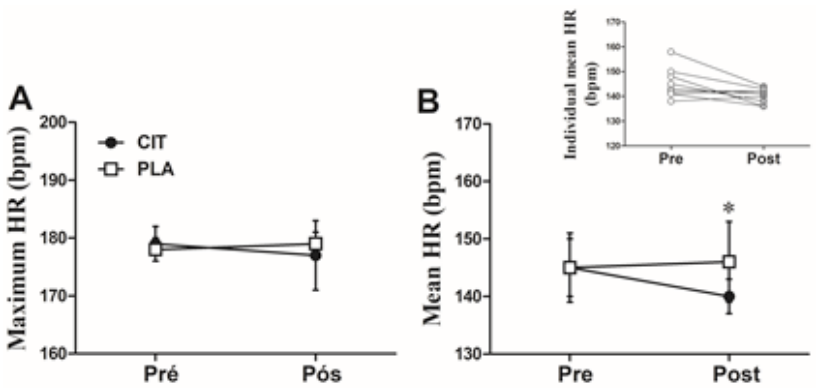

Source: Research data.

\subsection{Maximum number of repetitions}

No significant difference $(P>0.05)$ was found in the number of maximum repetitions between the CIT and PLA groups (Figure 4A) from the pre to the post-supplementation moment (CIT, Pre: $19 \pm 3$ and Post: $19 \pm 1$ vs. PLA, Pre 17 \pm 3 and Post: $17 \pm 2$ ). PSE (Borg 0-20) was also similar $(P>$ 0.05 ) between the CIT and PLA groups (Figure 4B) from the pre-supplementation moment (CIT, Pre: $16 \pm 2$ and Post: $16 \pm$ 2 vs. PLA, Pre $17 \pm 1$ and Post: $16 \pm 2$ ).

Figure 4 - Number of maximum repetitions (A) and subjective effort perception (PSE) (B) in malate citrulline (CIT, $N=9$ ) and placebo groups (PLA, $N=9$ ) in pre- and post-supplementation moments. Values expressed in mean \pm SD. No significant difference $(P>0.05)$ was observed between the groups
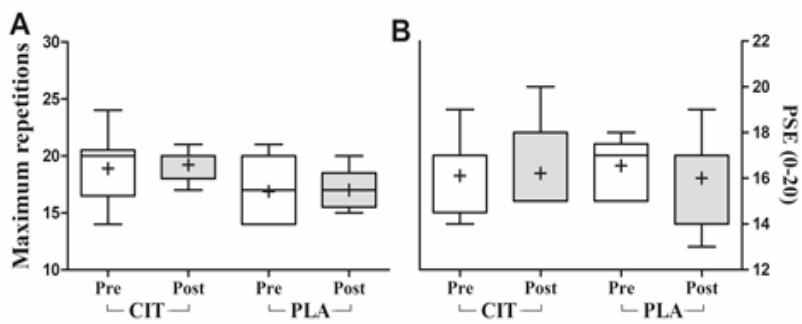

Source: Research data.

The objective of this study was to evaluate the effects of seven days of CIT supplementation (6 g/day) on aerobic resistance (time to exhaustion) and muscle resistance (number of maximum repetitions), in addition to HR (aerobic resistance indicator) and PSE (muscle resistance indicator) in young adults. The hypothesis was tested that CIT supplementation could increase the time until exhaustion and the number of maximum repetitions, as well as reduce HR (mean and maximum) and subjective effort perception (PSE). The main findings of the study were that: 1) CIT did not improve aerobic and muscular resistance, nor did it reduce maximum HR or PES; and 2) CIT reduced mean HR during the maximum incremental test on the treadmill. These findings refer to the assumption that CIT does not present ergogenic potential in maximum tests, despite reducing mean HR.

Contrary to the findings herein, previous studies ${ }^{28}$ observed that supplementation of $2.4 \mathrm{~g} /$ day of L-citrulline for 7 days promoted a $1.5 \%$ reduction in the time to complete a $4 \mathrm{~km}$ cycle route, with concomitant reduction in the PSE. It is worth pointing out that these favorable performance results were obtained in a sample of trained individuals, differently from this study involving a sample of university students who did not practice physical activity regularly. This could explain, at least partially, the lack of ergogenic effect found in this study compared to the study by Suzuki et al. ${ }^{28}$, and suggests that the CIT beneficial effects may be dependent on the physiological condition of each individual.

Curiously, Hickner et al. ${ }^{29}$ demonstrated that L-citrulline supplementation ( $9 \mathrm{~g}$, fractioned in 3 doses of $3 \mathrm{~g} ; 24$ hours before the test) reduced the performance in the exhaustion test (treadmill run) and increased the PSE in physically active young adults. The authors report that L-citrulline supplementation may affect test performance until exhaustion, due to a supposed negative effect on the relationship between ON synthesis and degradation. However, such negative effects of citrulline on physically active young adults also suggest that $\mathrm{ON}$ precursors may be more effective in individuals with reduced ON production or availability, which would impair blood or metabolic flow. In physically active young people with integral vascular health (e.g. ON production and vasodilation) citrulline would be inefficient or could even affect performance. In addition, there may be specific differences in these populations regarding the conversion of L-citrulline to L-arginine, as well as the subsequent $\mathrm{ON}$ formation, which could negatively influence the physical performance. However, Bailey et al. ${ }^{30}$ used an L-citrulline supplementation protocol ( $6 \mathrm{~g}$ /day for 7 days) very similar to that of the present investigation and observed improvement of VO2 kinetics and consequent improvement in general performance during a high intensity test on a cycle ergometer in healthy adults. Therefore, considering the discrepancy between the findings of previous studies ${ }^{28-30}$ and this study, it seems premature to consider CIT supplementation as a potential geogenic resource for improving aerobic resistance.

In addition, Pérez-guisado \& Jakeman ${ }^{8}$ investigated the effects of a high acute CIT dose $(8 \mathrm{~g})$ and verified improvement in anaerobic performance and reduction of post- 
exercise muscle pain, suggesting a possible CIT remedial role. It was also demonstrated in another investigation ${ }^{31}$ that the intake of $500 \mathrm{ml}$ of pure watermelon juice (corresponding to $1.17 \mathrm{~g}$ citrulline) enriched with citrulline (4.83g of citrulline + $1.17 \mathrm{~g}$ of citrulline corresponding to the juice) was capable of significantly reducing muscle pain 24 hours after a session of high intensity exercises on the cycle ergometer, in addition to contributing to HR recovery after exercise.

In this study, CIT reduced mean HR during the aerobic resistance test. This fact agrees with the hypothesis tested, since vascular relaxation may favor a greater systolic volume and consequently a lower cardiovascular cost, allowing for a reduction in HR. Several studies ${ }^{32-34}$ have already demonstrated that $\mathrm{ON}$ promotes increased capillary permeability, which would favor increased blood flow to the active muscles, providing greater supply of nutrients and oxygen, as well as greater removal of metabolic degradation substrates, resulting in higher performance. However, this physiological facilitation did not reflect on performance improvement in the present study, since there were no differences in time to exhaustion. Anyway, the limiting factor for performance may be linked to the capacity of metabolic substrates use, especially considering the level of population training in the present study. Thus, the increase in aerobic performance promoted by L-citrulline supplementation in trained individuals ${ }^{28}$ can be attributed to the higher cellular use capacity of energy substrates.

On the other hand, researchers presented results contrary to those observed in the present study. Sánchez-Martínez et al. ${ }^{35}$ found that the intake of watermelon juice enriched with $3.45 \mathrm{~g}$ of citrulline did not reduce the mean HR of amateur runners in a half-marathon race. In any case, it is necessary to consider experimental differences, such as the populations studied and the supplementation protocols (dose, fractionation and period) make it difficult to establish a consensus regarding the beneficial CIT effects on HR and performance. However, it is worth pointing out that interpersonal responsiveness can also be a determining factor for the CIT effects on mean HR, since in this study, the reduction in mean HR was evidenced in $75 \%$ of the sample participants, while $25 \%$ remained without effect.

The present investigation has also not demonstrated the effects of CIT supplementation on muscle resistance (maximum repetitions), as well as on PSE. These results corroborate previous studies ${ }^{36,37}$ that did not identify ergogenic benefits in muscle resistance. In line with the present study, Cutrufello et al. ${ }^{13}$ examined the ingestion effects of a single dose of L-citrulline $(6 \mathrm{~g})$ or $710 \mathrm{ml}$ of watermelon juice (approximately $1 \mathrm{~g}$ of citrulline) on the number of repetitions achieved in the bench press exercise, time to exhaustion, maximum oxygen consumption and anaerobic threshold during a maximum treadmill test. In their results, these authors report that the doses of L-citrulline used were ineffective in improving performance in the exercises performed, and no significant improvement was observed in the variables analyzed in relation to the individuals who ingested placebo.

Data concerning PSE in the present study are in line with previous studies ${ }^{29,35,38}$, which also did not observe effect of citrulline supplementation on PSE. However, Suzuki et al. ${ }^{28}$ and Glenn et al. ${ }^{39}$ reported a reduction in PSE using chronic ( $2.4 \mathrm{~g} /$ day for 7 days) and acute ( $8 \mathrm{~g}$ ) supplementation of citrulline, respectively. It is important to consider that the PSE involves, in addition to the sensation of pure effort, a complex of internal and external stimuli, which may not be directly linked to the sensory organs ${ }^{40}$. Thus, during physical efforts a set of sensations (e.g. heat, tension, vision, etc.) are perceived simultaneously, so that the interpretation of these sensations is very specific, making comparisons difficult.

Some limitations of this study should be highlighted. No tests were carried out to analyze the plasma citrulline concentration and $\mathrm{ON}$ bioavailability markers (e.g., nitrite and nitrate), however, previous studies that used the same dose (6g/day) used in this study showed an increase in the plasma concentration of this amino acid ${ }^{26}$. The participants' diet was not standardized during the experimental period either.

\section{Conclusion}

CIT supplementation (6 g/day) is not capable of improving aerobic and muscle resistance, as well as reducing maximum HR or PES in healthy young adults. However, CIT supplementation may reduce the mean HR during aerobic resistance exercise. Future studies are necessary to confirm the effectiveness of different CIT amino acid doses in different populations (trained vs. untrained; young vs. elderly; men vs. women) and types of exercises (aerobic vs. anaerobic), before considering it as a potential ergogenic resource in different health and performance conditions.

\section{Acknowledgments}

Universidade Parananese (UNIPAR) for the financial support to carry out this study.

\section{References}

1. Alvares TS, Meirelles CIT, Bhambhani YN, Paschoalin VM, Gomes PS. L-Arginine as a potential ergogenic aid in healthy subjects. Sports Med 2011;41(3):233-48. doi: https://doi. org/10.2165/11538590-000000000-00000

2. Bendahan D, Mattei JP, Ghattas B, Confort-Gouny S, Le Guern ME, Cozzone PJ. Citrulline/malate promotes aerobic energy production in human exercising muscle. Br J Sports Med 2002;36(4):282-89. doi: http://dx.doi.org/10.1136/ bjsm.36.4.282

3. Bescos R, Sureda A, Tur JÁ, Pons A. The effect of nitric-oxiderelated supplements on human performance. Sports Med 2012;42(2):99-117. doi: https://doi.org/10.2165/11596860000000000-00000

4. Rougé C, Des Robert C, Robins A, Le Bacquer O, Volteau $\mathrm{C}$, De La Cochetière MF, et al. Manipulation of citrulline availability in humans. Am J Physiol Gastrointest Liver 
Physiol 2007;293(5):1061-7. doi: https://doi.org/10.1152/ ajpgi.00289.2007

5. Sureda A, Cordova A, Ferrer MD, Tauler P, Perez G, Tur JA, Pons A. Effects of 1- citrulline oral supplementation on polymorphonuclear neutrophils oxidative burst and nitric oxide production after exercise. Free Radic Res 2009;43:82835. doi: 10.1080/10715760903071664

6. Thibault R, Flet L, Vavasseur F, Lemerle M, FerchaudRoucher V, Picot D, et al. Oral citrulline does not affect whole body protein metabolism in healthy human volunteers: results of a prospective, randomized, double-blind, cross-over study. Clin Nutr 2011;30(6):807-11. doi: https://doi.org/10.1016/j. clnu.2011.06.005

7. Bloomer RJ. Nitric oxide supplements for sports. J Strength Cond Res 2010;32:14-20. doi: 10.1519/ SSC.0b013e3181bdaf89

8. Perez-Guisado J, Jakeman PM. Citrulline malate enhances athletic anaerobic performance and relieves muscle soreness. J Strength Cond Res 2010;24(5):1215-22. doi:10.1519/ JSC.0b013e $3181 \mathrm{cb} 28 \mathrm{e} 0$

9. Little JP, Forbes SC, Candow DG, Cornish SM, Chilibeck PD. Creatine, arginine alphaketoglutarate, amino acids, and medium-chain triglycerides and endurance and performance. Int J Sport Nutr Exerc Metab 2008;18(5):493-508. doi: https://doi.org/10.1123/ijsnem.18.5.493

10. Wilcock IM, Cronin JB, Hing WA. Physiological response to water immersion: a method for sport recovery? Sports Med 2006;36(9):747-65. doi: https://doi.org/10.2165/00007256200636090-00003

11. Briand J, Blehaut H, Calvayrac R, Laval-Martin D. Use of a microbial model for the determination of drug effects on cell metabolism and energetics: study of citrulline-malate. Biopharm Drug Dispos 1992;13(1):1-22. doi: https://doi. org/10.1002/bdd.2510130102

12. Curis E, Nicolis I, Moinard C, Osowska S, Zerrouk N, Benazeth S, et al. Almost all about citrulline in mammals. Amino Acids 2005;29(3):177-205. doi: https://doi. org/10.1007/s00726-005-0235-4

13. Cutrufello PT, Gadomski SJ, Zavorsky GS. The effect of L-citrulline and watermelon juice supplementation on anaerobic and aerobic exercise performance. J Sports Sci 2015;33(14):1459-66. doi: https://doi.org/10.1080/02640414 .2014 .990495

14. Breuillard C, Cynober L, Moinard C. Citrulline and nitrogen homeostasis: an overview. Amino Acids 2015;47(4):685-91. doi: https://doi.org/10.1007/s00726-015-1932-2

15. Wax B, Kavazis AN, Luckett W. Effects of supplemental citrulline-malate ingestion on blood lactate, cardiovascular dynamics, and resistance exercise performance in trained males. J Diet Suppl 2015;13(3):269-282. doi: https://doi.org/ $10.3109 / 19390211.2015 .1008615$

16. Vanuxem D, Duflot JC, Prevot H, Bernasconi P, Blehaut $\mathrm{H}$, Fornaris E, et al. Influence of an anti- asthenia agent, citrulline malate, on serum lactate and ammonia kinetics during a maximum exercise test in sedentary subjects. Semin Hop Paris 1990;66:477-481.

17. Sureda A, Pons A. Arginine and cittruline supplementation in sports and exercise: ergogenic nutrients. Med Sport Sci 2012;59:18-28. Doi: https://doi.org/10.1159/000341937

18. Takeda K, Machida M, Kohara A, Omi N, Takemasa T. Effects of citrulline supplementation on fatigue and exercise performance in mice. J Nutr Sci Vitaminol 2011;57(3):246-
250. doi: https://doi.org/10.3177/jnsv.57.246

19. da Silva DK, Jacinto JL, de Andrade WB, Roveratti MC, Estoche JM, Balvedi MCW, et al. Citrulline malate does not improve muscle recovery after resistance exercise in untrained young adult men. Nutrients 2017;9(10):E1132. Doi: https://doi.org/10.3390/nu9101132

20. Glenn J, Gray M, Wethington L, Stone M, Stewart R, Moyen N. Acute citrulline-malate supplementation improves upper- and lower-body submaximal weightlifting exercise performance in resistance-trained females. Eur J Nutr 2017;56(2):775-84. doi: https://doi.org/10.1007/s00394-015-1124-6

21. Chappell A, Allwood DM, Johns R, Brown S, Sultana K, Anand A, et al. Citrulline malate supplementation does not improve german volume training performance or reduce muscle soreness in moderately trained males and females. J Int Soc Sports Nutr 2018;15(1):1-10. doi: https://doi. org/10.1186/s12970-018-0245-8

22. Farney TM, Bliss MV, Hearon CM, Salazar DA. The Effect of Citrulline Malate Supplementation On Muscle Fatigue Among Healthy Participants. J Strength Cond Res 2017. doi: doi: 10.1519/JSC.0000000000002356

23. Borg G. Borg's Perceived Exertion and Pain Scales. Champaign (IL): Human Kinetics; 1998.

24. Campos GE, Luecke TJ, Wendeln HK, Toma K, Hagerman FC, Murray TF, et al. Muscular adaptations in response to three different resistance-training regimens: specificity of repetition maximum training zones. Eur J Appl Physiol 2002;88(1-2):50-60. doi: https://doi.org/10.1007/s00421002-0681-6

25. Bentley DJ, Newell J, Bishop D. Incremental exercise test design and analysis: implications for performance diagnostics in endurance athletes. Sports Med 2007;37(7):575-86. doi: https://doi.org/10.2165/00007256-200737070-00002

26. Sureda A, Córdova A, Ferrer MD, Pérez G, Tur JA, Pons A. L-Citruline-malate influence over branched amino acid utilization during exercise. Eur J Appl Physiol 2010;110(2):341-51. doi: https://doi.org/10.1007/s00421010-1509-4

27. Schwedhelm E, Maas R, Freese R, Jung D, Lukacs Z, Jambrecina A, et al. Pharmacokinetic and pharmacodynamics properties of oral L- citrulline and L-arginine: impact on nitric oxide metabolism. Br J Clin Pharmacol 2007;65(1):519. doi: https://doi.org/10.1111/j.1365-2125.2007.02990.x

28. Suzuki T, Morita M, Kobayashi Y, Kamimura A. Oral L-citrulline supplementation enhances cycling time trial performance in healthy trained men: double-blind randomized placebo-controlled 2-way crossover study. J Int Soc Sports Nutr 2016;13(6):1-8. Doi: https://doi.org/10.1186/s12970016-0117-z

29. Hickner RC, Tanner CJ, Evans CA, Clark PD, Haddock A, Fortune $\mathrm{C}$, et al. L-citrulline reduces time to exhaustion and insulin response to a graded exercise test. Med Sci Sports Exerc 2006;38(4):660-6. doi: 10.1249/01.mss.0000210197.02576. da

30. Bailey SJ, Blackwell JR, Lord T, Vanhatalo A, Winyard $\mathrm{PG}$, Jones AM. L-citrulline supplementation improves $\mathrm{O} 2$ uptake kinetics and high-intensity exercise performance in humans. J Appl Physiol 2015;119(4):385-95. doi: https://doi. org/10.1152/japplphysiol.00192.2014

31. Tarazona-Días MP, Alacid F, Carrasco M, Martínez I, Aguayo E. Watermelon juice: potential functional drink for sore muscle relief in athletes. J Agric Food Chem 2013;61(31):7522-8. 
doi: https://doi.org/10.1021/jf400964r

32. Moller AD, Grande PO. Role of prostacyclin and nitric oxide in regulation of basal microvascular hydraulic permeability in cat skeletal muscle. J. Vasc. Res 1999;36(3):245-52. doi: https://doi.org/10.1159/000025648

33. Plante GE, Perreault A, Lanthier A, Marette A, Maheux P. Reduction of endothelial NOS and bradykinin-induced extravasation of macromolecules in skeletal muscle of the fructose-fed rat model. Cardiovasc Res 2003;59(4):963-70. doi: https://doi.org/10.1016/S0008-6363(03)00521-2

34. Rumbaut RE, Mckay MK, Huxley VH. Capillary hydraulic conductivity is decreased by nitric oxide synthase inhibition. Am J Physiol 1995;268. doi: https://doi.org/10.1152/ ajpheart.1995.268.5.H1856

35. Martínez-Sánchez A, Ramos-Campo DJ, Fernández-Lobato B, Rubio-Arias JA, Alacid F, Aguayo E. Biochemical, physiological, and performance response of a functional watermelon juice enriched in L-citrulline during a halfmarathon race. Food Nutr Res 2017;61(1):1330098. doi: https://doi.org/10.1080/16546628.2017.1330098

36. Santos AC, Ferro JM. Profile of Anger in Acute Stroke:
A Multifactorial Model of Anger Determinants. J Neuropsychiatry Clin Neurosci 2019;31(2):159-64. doi: https://doi.org/10.1176/appi.neuropsych.18030037

37. Gonzalez AM, Spitz RW, Ghigiarelli JJ, Sell KM, Mangine GT. Acute Effect of Citrulline Malate Supplementation on Upper-Body Resistance Exercise Performance in Recreationally Resistance-Trained Men. J Strength Cond Res 2018;32(11):3088-94. doi: 10.1519/JSC.0000000000002373

38. Cunniffe B, Papageorgiou M, O’brien B, Davies NA, Grimble GK, Cardinale M. Acute citrulline-malate supplementation and high-intensity cycling performance. J Strength Cond Res 2016;30(9):2638-47. doi: https://doi.org/10.1519/ JSC.0000000000001338

39. Glenn JM, Gray M, Wethington LN, Stone MS, Stewart Jr RW, Moyen NE. Acute citrulline malate supplementation improves upper and lower-body submaximal weightlifting exercise performance in resistance-trained females. Eur $\mathbf{J}$ Nutr 2015;56(2):775-84. doi: https://doi.org/10.1007/s00394015-1124-6

40. Robertson RJ, Noble BJ. Perception of physical exertion: methods, mediators, and applications. Exerc Sport Sci Rev 1997;25:407-52. 